\title{
Preference for photographs as a function of frequency of presentation
}

WARNER WILSON AND HOLLY NAKAJO

UNIVERSITY OF HAWAII

\begin{abstract}
Abstraet
Frequency of presentation has been shown to increase preference for music and nonsense syllables. Evidence also suggests that frequency of interpersonal contact increases liking. These considerations led to the prediction that ratings of photographs of young men would become more favorable as a function of frequency of presentation. This prediction received support in a sample of 80 undergraduate females.

\section{Introduction}

This study was designed to test the hypothesis that ratings of persons in photographs would improve as a function of the frequency of presentation of the photographs. Three lines of evidence suggested this hypothesis. One is an increase in liking of non-social stimuli as a function of frequency of presentation. This hypothesis has been confirmed for nonsense syllables (Becknell, Wilson, \& Baird, 1963; Frincke \& Johnson, 1960; Johnson, Thomson, \& Frincke, 1960) and for music (Krugman, 1943; Mull, 1957)。 The second line of evidence is an increase in liking as a function of interpersonal contacts (Bovard, 1951; Festinger 1951; Homans, 1950; Sherif \& Sherif, 1956; Wilson \& Miller, 1961). A third line of evidence is a relation between propinquity and sociometric choice (Bossard, 1932; Davie \& Reeves, 1939; Deutsch \& Collins, 1951; Festinger, Schachter, \& Back, 1950; Newcomb, 1956; Schnepp \& Roberts, 1953). It does not seem unlikely that the important thing about propinquity may be that it allows for frequent contacts to occur.

\section{Method}

Subjects. Eighty University of Hawaii coeds enrolled in introductory psychology served as Ss. Participation was worth a small amount of extra credit in their psychology course.

Apparatus. Photographs of four boys (students at the University of Hawaii) were obtained, mounted on slides, and presented with a slide projector in a regular classroom. The photographs were all standard poses showing the upper half of the body with the name of the boy printed on the bottom of the slide. Duplicates were made of the slides in order to facilitate repeated presentation of the same stimuli.

Procedure. Four groups of 20 saw each photograph either 1, 4, 7, or 10 times. Each viewing lasted $10 \mathrm{sec}$. Each group of 20 was composed of several smaller groupings run at different times. The slides were arranged so that presentations of the same photograph would be spaced as widely as possible. The same sequence was then presented to every grouping of Ss except that the starting point within the sequence was determined randomly on each occasion.

After viewing the photographs the Ss gave a brief written description of each boy from memory. These descriptions confirmed prior studies which show that Ss form fairly rich impressions of personality on the basis of limited data. Secord \& Backman (1964, pp. 60-64) cite several such studies. In the present study the purpose of the written descriptions was to establish that each S had formed some impression of each person. This assurance was sought to guard against the possibility that the Ss would rate the infrequently presented photographs low merely because they had no memory of them at all. The rationale of the hypothesis seems to require that the Ss form an impression of the infrequent photographs that is relatively unfavorable rather than being simply non-existent. Several Ss who failed to put down a written description for each $\mathrm{S}$ were discarded. Also, it was noted that the most popular photograph maintained high popularity even when presented only 1 or 4 times. This fact also seems to give assurance that some impression was formed even with low frequencies of presentation.

Response measures. Several response measures were obtained. After writing the description, the S ranked each boy from 1 to 4 on the basis of all-round desirable personality traits. This ranking provided one dependent variable. Next the Ss ranked each boy from 1 to 4 on a number of designated traits. These were divided a priori into four groups: Aspects of Social Appeal: fun to be with, sex appeal, charming, friendly, attractive, desirable as a date, good looking, (not) mean, likeable, and (not) hostile; Traits of Emotional Stability: (not) moody, (not) agressive, (not) emotionally unstable, (not) neurotic, and (not) anxious; Character Traits: cooperative, trustworthy, loyal, honest, and (not) greedy; and Ability Traits: intelligent, orderly, capable, effective, and industrious. Rankings on all the traits of a given type were combined, and the four types of traits then provided four more dependent variables. Utilizations of all four ranks derived from a given S did not seem appropriate as the rank a $\mathrm{S}$ gave one photograph was obviously not independent of the ranks received by the other photographs. On the other hand, it seemed desirable to derive one score for each $\mathrm{S}$ on each dependent variable which would reflect as much information as possible. In order to accomplish this goal the ranks each $\mathrm{S}$ gave to the two frequently presented photo- 
graphs were compared to those given to the two infrequently presented photographs. If the $S$ gave the frequently presented photographs higher rankings on a given dependent variable, he was counted as supporting the hypothesis. Ties were evenly distributed in the supporting and non-supporting categories. Separate chi square tests were employed to test the significance of the effect of frequency of presentation on each dependent variable.

\section{Hesults and Discussion}

Table 1 indicates the number of times high versus low frequency of presentation resulted in higher rankings on each of the five dependent variables. On all five variables the trend is in the predicted direction of higher ratings for more frequently presented photographs. These trends attain satisfactory levels of significance only in the case of the "Desirable Personality," "Social Appeal," and "Emotional Stability" measures. Although the "Character" and "Ability" measures show weaker trends these are not significantly different from the others. It would not be especially surprising, however, if subsequent research proved some of these variables to be less sensitive to a frequency manipulation than others. In any case, with all five trends going in the predicted direction and three attaining significance, the data seem to offer satisfactory support for the hypothesis.

Generalization from simple stimuli such as nonsense syllables to more complex and socially relevant stimuli such as photographs seems, therefore, to be successful;

Table 1. Number of Times High Frequency Photographs Received High and Low Rankings on Five Dependent Variables

\begin{tabular}{lccccc}
\multicolumn{7}{c}{ Variable } \\
\hline & $\begin{array}{l}\text { Desirable } \\
\text { Personality }\end{array}$ & $\begin{array}{c}\text { Social } \\
\text { Appeal }\end{array}$ & $\begin{array}{c}\text { Emotional Character } \\
\text { Stability }\end{array}$ & $\begin{array}{c}\text { Ability } \\
\text { Traits }\end{array}$ & Traits \\
\hline High Rankings & 51 & 54 & 50 & 47 & 46 \\
Low Rankings & 29 & 26 & 30 & 33 & 34 \\
Chi Square & 6.05 & 9.80 & 5.00 & 2.45 & 1.80 \\
PValues & $<.02$ & $<.005$ & $<.03$ & .25 & $<.25$ \\
\hline
\end{tabular}

and the ubiquitous influence of frequency is reaffirmed. Generalization to actual social contacts requires great caution, of course, but the data at least suggest that familiarity does not breed contempt and that a young man wishing to make an impression on the girl of his choice may hope to improve in favor as a function of frequent encounters so long as he can keep his own behavior from being noxious.

\section{References}

Becknell, J. C., Jr., Wilson, W. R., \& Baird, J. C. The effect of frequency of presentation on the choice of nonsense syllables. J. Psychol., 1963, 56, 165-170.

Bossard, J. H. S. Residential propinquity as a factor in marriage selection. Amer. J. Sociol., 1932, 38, 219-224.

Bovard, E. W., Jr. Group structure and perception. J. abnorm. soc. Psychol., 1951, 46, 398-405.

Davie, M. R., \& Reeves, R. J. Propinquity of residence before marriage. Amer. J. Sociol., 1939, 44, 510-517.

Deutsch, M., \& Collins, M. E. Interracial housing: A psychological evaluation of a social experiment. Minneapolis: University of Minnesota Press, 1951.

Festinger, L. Group attraction and membership. J. soc. Issues, 7 152-163.

Festinger, L., Schachter, S., \& Back, K. Social pressures in in formal groups. New York: Harper, 1950.

Frincke, G., \& Johnson, R. C., Word value and word frequency in homophone pairs. Psychol. Rep., 1960, 7, 470.

Homans, G. C. The human group. New York: Harcourt, Brace, 1950

Johnson, R. C., Thomson, C. W., \& Frincke, G. Word value, word frequency and visual duration thresholds. Psychol. Rev., 1962, $69,332-342$

Krugman, H. E. Affective response to music as a function of familiarity. J. abnorm. soc. Psychol., 1943, 38, 338-392.

Mull, Helen, K. The effect of repetition upon the enjoyment of modern music. J. Psychol., 1957, 43, 155-162.

Newcomb, T. M. The prediction of interpersonal attraction. Amer. Psychologist, 1956, 11, 575-586.

Schnepp, G. J., \& Roberts, L. A. Residential propinquity and mate selection on a parish basis. Amer. J. Sociol., 1953, 48, 45-50.

Secord, P. F., \& Backman, C. W. Social psychology. New York: McGraw-Hill, 1964.

Sherif, M., \& Sherif; Carolyn W. An outline of social psy'chology. New York: Harper, 1956.

Wilson, W., \& Miller, N. Shifts in evaluations of participants following intergroup interaction. J. abnorm. soc. Psychol., 1961, $63,428-431$. 